\title{
Research on Axial Stiffness of the Double-nut Ball Screw Mechanism
}

\author{
Song Xian-chun \\ School of Mechanical and Electronic Engineering, Shandong \\ jianzhu University, Jinan 250101, China \\ Chen Ming-yuan \\ School of Mechanical and Electronic Engineering, Shandong \\ jianzhu University, Jinan 250101, China
}

\author{
Song Jian \\ School of Mathematics, Shandong University, Jinan \\ 250014, China \\ Li Yan-feng \\ School of Mechanical and Electronic Engineering, \\ Shandong jianzhu University, Jinan 250101, China \\ School of Mechanical Engineering \\ Shandong University, Jinan 250014, China \\ liayanafenga@163.com
}

\begin{abstract}
Contact stress analysis on the high-speed double-nut ball screw has been done, contact deformation has been derived, and we got the formulas of axial stiffness of ball screws, and then we got some main factors which could influence the axial stiffness of ball screws, such as preload, helix angle, contact angle ,etc. Then we got the influence on ball screws caused by these factors and the corresponding related curves, which can provide theoretical support for the reasonable design on new high-speed ball screws.
\end{abstract}

Keywords-contact angle; double-nut preload; ball screws; axial stiffness; influencing factors

\section{INTRODUCTION}

With the widely application of digital control technology, the development of ball screws oriented to high-speed, highprecision and low-carbon ${ }^{[1]}$. The ball screw with large pitch becomes one of the important ways of high-speed. As the key component of numerical control machine tools, it must ensure the processing accuracy when the trend of ball screws towards to high-speed. The influence of axial stiffness on the positioning accuracy of ball screws becomes increasingly obviously. Especially in the transmission system of the machine tool, axial stiffness of ball screws is relatively a weak link ${ }^{[2]}$. Therefore the research on axial stiffness of high-speed ball screws has important theoretical and practical significance. Which KD4020-3 Type double-nut ball screws is studied in this article, we proposed the impact of different factors on axial stiffness of ball screws. Without loss of generality, the conclusion provides a theoretical reference to other types of ball screws.

\section{THEORY ANALYSIS}

\section{A. Analysis of the Double-nut ball screw mechanism}

In order to eliminate the axial clearance of ball screws and improve its axial stiffness, it always uses double-nut structure ${ }^{[3]}$. The working principle of double-nut ball screws is shown in Fig.1.It shows that the nut A, B and screw raceway contact at point A, B by gasket respectively, and the direction of the contact angle opposite ${ }^{[4]}$.

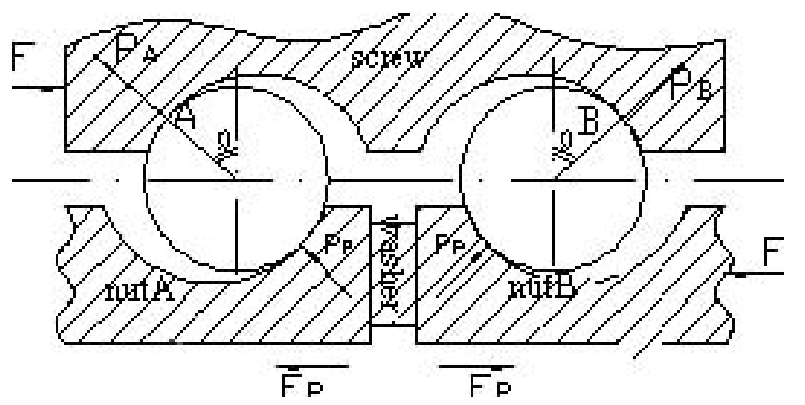

Figure 1. Stress Analysis of double-nut ball screws.

Where $P_{A}, P_{B}$ are the normal pressure of the nut $\mathrm{A}, \mathrm{B}$ and screw raceway respectively, $F_{P}$ is the preload of gasket, $P_{P}$ is the normal preload, $Z$ is the ball number, $\lambda$ is the helix angle, $\beta$ is the contact angle, therefore,

$$
F_{P}=P_{P} \sin \beta \cos \lambda
$$

If the axial external loads $F=0$, we can obtain,

$$
P_{A}=P_{B}=P_{P}
$$

From Fig.1, if the axial external loads $F \neq 0$, under the role of load $\mathrm{F}$, the contact point of nut A elastic deformation increases, and the normal pressure of screw raceway will also add an additional normal pressure $P_{1}$, oppositely the nut $\mathrm{B}$ reduces a normal pressure $P_{2}$,

$$
\begin{aligned}
& P_{A}=P_{P}+P_{1} \\
& P_{B}=P_{P}+P_{1}
\end{aligned}
$$

National natural science foundation of China (Project \# 51075246),

Science Technology Development Program of Shandong Province

(2008GG10004009). 
Based on the static equilibrium, the average normal force can be expressed as follows,

$$
\begin{aligned}
& F-\left(P_{P}+P_{1}\right) Z \sin \beta \cos \lambda+ \\
& \left(P_{P}-P_{2}\right) Z \sin \beta \cos \lambda=0
\end{aligned}
$$

Assuming $P=P_{1}+P_{2}$, after finishing,

$$
\begin{aligned}
& F=\left(P_{1}+P_{2}\right) Z \sin \beta \cos \lambda \\
& P=F /(Z \sin \beta \cos \lambda)
\end{aligned}
$$

As shown in formula (5), $P$ is the average normal force of single nut under the action of external loads $F$.

\section{B. Elastic Deformation of the Double-nut ball screw mechanism}

\section{1) Elastic Deformation without Load}

Under the role of preload $F_{P}$, no-load ball screws will still produce axial deformation and nuts and gaskets are deformed. However, the amount of axial deformation can be ignored compared with the deformation of the contact between the balls and the raceways for the reason of surface contact ${ }^{[5]}$.

Due to the same normal preload of two nuts, the axial contact deformation of nuts is also the same and the deformation can be obtained,

$$
\delta_{P}=K^{\prime} P_{P}^{\frac{2}{3}}
$$

Where $K^{\prime}$ is a constant which depends on the physical dimension and materials.

$$
\begin{aligned}
& K^{\prime}=\frac{1}{\pi}\left[\frac{3}{2}\left(\frac{1-\mu_{1}^{2}}{E_{1}}+\frac{1-\mu_{2}^{2}}{E_{2}}\right)\right]^{\frac{2}{3}}\left[\frac{K_{n}(e)}{m_{n a}}\left(\sum \rho_{n}\right)^{\frac{1}{3}}\right. \\
& \left.+\frac{K_{S}(e)}{m_{s a}}\left(\sum \rho_{s}\right)^{\frac{1}{3}}\right] \cos \lambda \sin ^{-1} \beta
\end{aligned}
$$

Combining formula (1) and (6), we can derive:

$$
\delta_{P}=K^{\prime}\left(\frac{1}{Z \sin \beta \cos \lambda}\right)^{\frac{2}{3}} F_{P}^{\frac{2}{3}}=K F_{P}^{\frac{2}{3}}
$$

$\mathrm{K}$ is the coefficient of axial contact deformation.

\section{2) Elastic Deformation under Load}

Assuming that $P_{A}$ is the total normal force of a single ball on the nut A, which on the role of the axial load. So the amount of axial deformation $\delta$ of the nut A on the role of $P_{A}$ can be obtained,

$$
\delta=K^{\prime} P_{A}^{\frac{2}{3}}
$$

The amount of axial deformation $\delta_{A}$, which generated by the axial load $\mathrm{F}$ can be expressed as,

$$
\delta_{A}=\delta-\delta_{P}
$$

Therefore,

$$
\begin{aligned}
& \delta_{A}=K^{\prime}\left[P_{A}^{\frac{2}{3}}-P_{P}^{\frac{2}{3}}\right]=K^{\prime} P_{P}^{\frac{2}{3}}\left[\left(\frac{P_{A}}{P_{P}}\right)^{\frac{2}{3}}-1\right] \\
& \left.=\delta_{P}\left[\left(\frac{P_{A}}{P_{P}}\right)^{\frac{2}{3}}-1\right)\right]
\end{aligned}
$$

After transformation of the above formula, can be obtained,

$$
\frac{P_{A}}{P_{P}}=\left(1+\frac{\delta_{A}}{\delta_{P}}\right)^{\frac{2}{3}}
$$

By putting the formula (2) into (12), we can obtain:

$$
\frac{P}{P_{P}}=\left(1+\frac{\delta_{A}}{\delta_{P}}\right)^{\frac{2}{3}}-\left(1-\frac{\delta_{A}}{\delta_{P}}\right)^{\frac{2}{3}}
$$

The latter two of expression (13) is expanded using power series expansion and take the first two, then we can obtain,

$$
\begin{aligned}
& \left(1+\frac{\delta_{A}}{\delta_{P}}\right)^{\frac{2}{3}} \approx 1+\frac{3}{2} \frac{\delta_{A}}{\delta_{P}} \\
& \left(1-\frac{\delta_{A}}{\delta_{P}}\right)^{\frac{2}{3}} \approx 1-\frac{3}{2} \frac{\delta_{A}}{\delta_{P}}
\end{aligned}
$$

So formula (13) can be expressed as,

$$
\frac{P}{P_{P}} \approx 3 \times \frac{\delta_{A}}{\delta_{p}}
$$

Thus it proved that deformation curve of double-nut ball screws is nearly linear relationship, which lots of technical information mentioned.

\section{Stiffness of the Double-nut ball screw Mechanism}

By the formula (15), we can obtain,

$$
\delta_{A}=\frac{1}{3} \delta_{P} \frac{P}{P_{P}}
$$

The following formula can be obtained by substituting expressions (6) and (7) into expression (16),

$$
\begin{aligned}
& \delta_{A}=\frac{1}{3 \pi}\left[\frac{3}{2}\left(\frac{1-\mu_{1}^{2}}{E_{1}}+\frac{1-\mu_{2}^{2}}{E_{2}}\right)\right]^{\frac{2}{3}}\left[\frac{K_{n}(e)}{m_{n a}}\left(\sum \rho_{n}\right)^{\frac{1}{3}}\right. \\
& \left.+\frac{K_{S}(e)}{m_{s a}}\left(\sum \rho_{s}\right)^{\frac{1}{3}}\right] Z^{\frac{2}{3}} \sin ^{\frac{5}{3}} \beta \cos ^{\frac{1}{3}} \lambda F_{P}^{\frac{1}{3}} F
\end{aligned}
$$




$$
\begin{aligned}
& K=\frac{1}{3 \pi}\left[\frac{3}{2}\left(\frac{1-\mu_{1}^{2}}{E_{1}}+\frac{1-\mu_{2}^{2}}{E_{2}}\right)\right]^{\frac{2}{3}}\left[\frac{K_{n}(e)}{m_{n a}}\left(\sum \rho_{n}\right)^{\frac{1}{3}}\right. \\
& \left.+\frac{K_{s}(e)}{m_{s a}}\left(\sum \rho_{s}\right)^{\frac{1}{3}}\right] Z^{\frac{2}{3}} \sin ^{\frac{5}{3}} \beta \cos ^{\frac{1}{3}} \lambda F_{P}^{\frac{1}{3}}
\end{aligned}
$$

$\mathrm{K}$ is the axial contact stiffness of ball screws.

Axial stiffness of double-nut ball screws is influenced by ball number, contact angle, helix angle, preload and so on.

It should be noted that the contact deformation caused by load reduced, while the deformation of the nut and raceway increases.

\section{Analysis the influence of Stiffness on the Double-nut Ball Screw mechanism}

The following is analysis the effects of stiffness on KD4020-3 ball screws. The following table1shows that the concrete parameters of KD4020-3 ball screw,

TABLE I. PARAMETERS OF KD4020-3 BALL SCREW

\begin{tabular}{|ll|c|}
\hline \multicolumn{2}{|c|}{ parameters } & values \\
\hline Young's Modulus & $(\mathrm{MPa})$ & 207000 \\
Poisson's Ratio & $\mu$ & 0.3 \\
Contact Angle & $\beta$ & $45^{\circ}$ \\
Helix Angle & $\lambda$ & $9^{\circ} 02^{\prime}$ \\
Nominal Diameter & $\mathrm{d}(\mathrm{mm})$ & 40 \\
Raceway Radius & $\mathrm{R}(\mathrm{mm})$ & 3.21462 \\
Ball Number & $\mathrm{Z}$ & 63 \\
\hline
\end{tabular}

1) Influence of the load on the double-nut ball screw stiffness

Assuming that the preload of double-nut ball screws is $10 \mathrm{KN}$, axial load is between $1 \mathrm{KN}$ and $80 \mathrm{KN}$, the change of contact stiffness with load is shown in Fig.2, according to the formula (18).

According to the formula (15), contact deformation is proportional to the load basically, the bigger the load, the bigger the deformation, but the stiffness values remain unchanged. As the influence of the contact surface, the deformation stiffness declined slightly along with the load changes from $1 \mathrm{KN}$ to $80 \mathrm{KN}$. Stiffness of ball screws becomes stable basically after it reduces from $780 \mathrm{~N} / \mu \mathrm{m}$ to $760 \mathrm{~N} / \mu \mathrm{m}$, kept a good location accuracy.

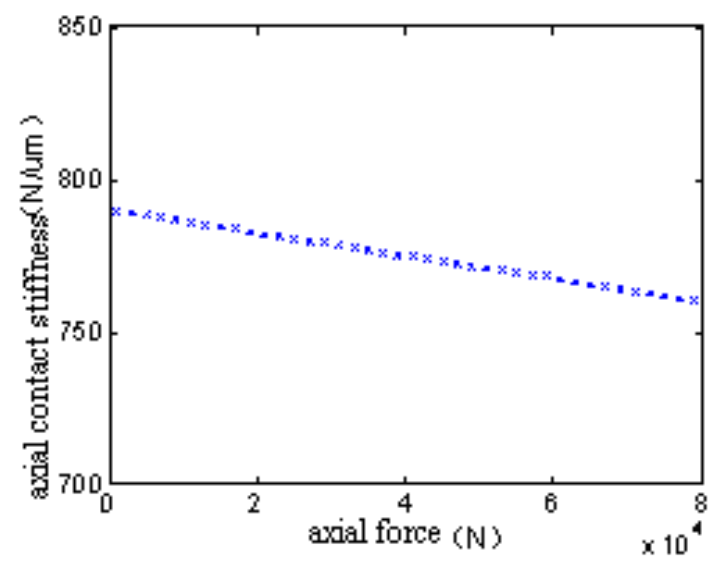

Figure 2. The influence of axial force on the double-nut ball screw stiffness.

2) Influence of preload on the double-nut ball screw stiffness

The most difference between single and double-nut ball screws is preload. The change of stiffness of double-nut ball screws with different preload is shown in Fig.3.

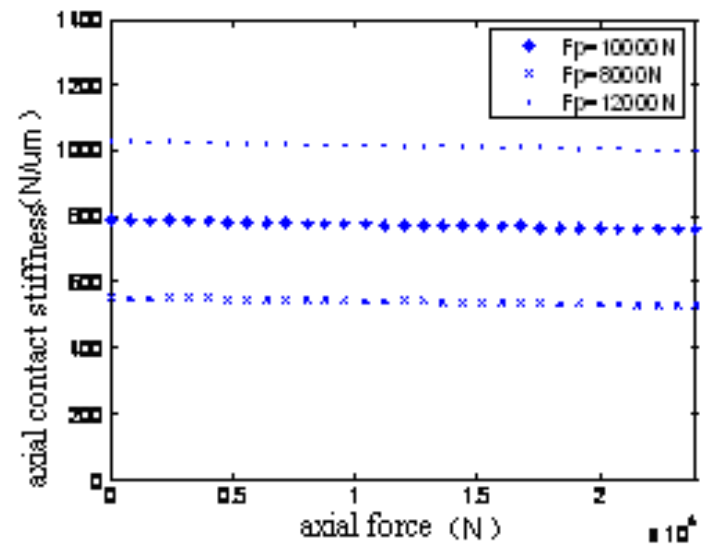

Figure 3. The influence of axial force on the double-nut ball screw stiffness

It is shown that the improvement of double-nut ball screw stiffness can significantly improve the axial stiffness and positioning accuracy in Fig.3.But the ball screws under the load of preload only reduces the elastic deformation caused by load, and it has a minor impact on the elastic contact deformation between raceway and balls, compared with no preloaded single-nut ball screw mechanism. Due to the large contact stress and deformation, large preload can improve the axial stiffness. But it will also reduce the service life of products.

3) Influence of contact angle on the double-nut ball screw stiffness

In the normal section of thread track, the contact angle ( $\beta$ angle is shown in Fig.1) is located between the attachment of ball center and contact point of raceway and the perpendicular of thread rolling track axis. Assuming that the preload is $2 \mathrm{KN}$, the change trend is shown that axial stiffness increases from 30 to 70 with contact angle in Fig. 4.

Contact angle has great influences on the performance of the ball screw, the bearing capacity of ball screws increases 
with the increase of contact angle $\beta$. On the contrary, with the reducing of contact angle $\beta$, the bearing capacity of screw descend, in addition, the service life of products is affected as radial force increasing. Therefore, Taking the beneficial of transmission, bearing performance and the fluency of ball into account, we often adopt $\beta=45^{\circ}$ as the standard of contact angle at home and abroad.

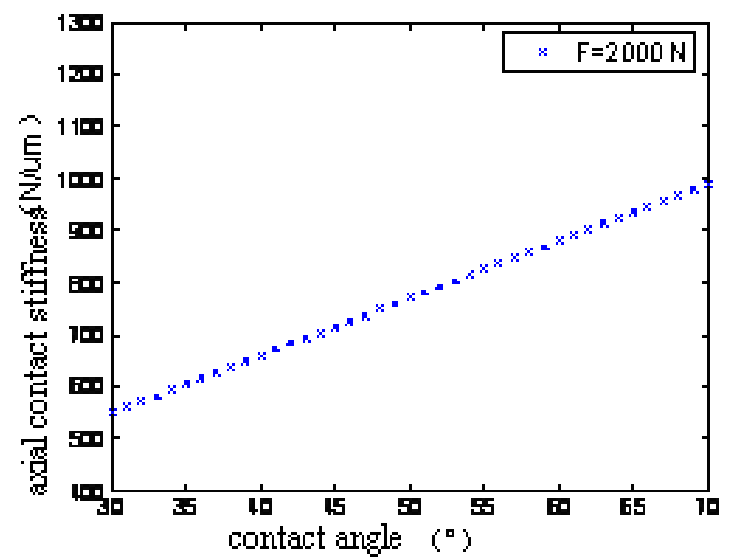

Figure 4. The influence of contact angle on the double-nut ball screw stiffness

4) Influence of helix angle on the double-nut ball screw stiffness

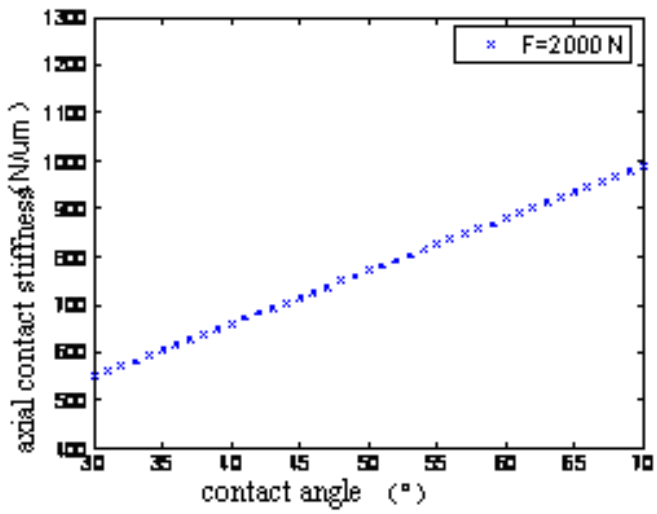

Figure 5. The influence of Helix angle on the stiffness of double-nut ball screw

Helix angle is one of the most important parameters of the high-speed ball screw. In order to adapt to the requirement of high speed, most of the high-speed ball screws has large pitch, which it is achieved by increasing the ball screw's helix angle. It is essential to consider the ball screw stiffness impacted by helix angle in the design process of high-speed ball screws. Taking the preload $2 \mathrm{KN}$, the change trend of axial stiffness with the helix angle to increases from $4^{\circ}$ to $25^{\circ}$ is shown in Fig. 5.

From the fig.5, it can be seen that the axial stiffness goes up with the increase of helix angle obviously, and the increase of helix angle also improves the feed speed of the screw. However, it will also increase lead error of ball screws and difficult of the high precision feed. So the proper enlargement of helix angle can improve ball screws stiffness and feed speed under the consideration of accuracy.

\section{CONCLUSION}

According to the above analysis of the influence on the axial stiffness of ball screws, the following conclusions can be drawn:

Contact angle and preload have great impact on axial contact stiffness of the double-nut ball screw, the stiffness of ball screws can be improved obviously by increasing the contact angle or the proper enlargement of preload, but too big preload or contact angle will also intensify the wear in the operation process. The increasing of helix angle will improve the axial rigidity of ball screws, at the same time; it will also improve the feed speed and meet the requirements of high speed. The conclusion can be also applicable to other types of ball screws; it provides a theoretical reference for the optimization design of new ball screws.

\section{REFERENCES}

[1] [1] M. Ninomiya and K. Miyaguchi, "Recent technical trends in ball screws", NSK Tech Journal: Motion Control, 664(1998): pp.1-3.

[2] [2] HIWIN, "Technical strategy for high-speed ball screw units", Manufacturing Technology \& Machine Tool, 12(2003): pp.87-88.

[3] [3] H.K.Jiang, X.C. Song and Z.Y. Zhang, "Dynamics analysis and simulation of re-circulating mechanism in ball screw", Proceedings of the 12th International Manufacturing Conference, Xi'an, China, pp.223227, 2006.

[4] [4]Chin Chung Wei, Jen Fin Lin .Kinematic Analysis of the Ball Screw Mechanism ConsideringVariable Contact Deformations [J]. Journal of Mechanical Design, 2003(125):717-733.

[5] [5]Xuesong Mei, Masaomi Tsutsumi, Tao Tao, Nuogang Sun. Studyon the load distribution of ball screws with errors [J].Mechanism and Machine Theory, 2003,V38 (11): 1257-1269. 